The present paper below is an original authors' working draft version that led to an article publication. A reference in APA settings to this work should always be done using the following citation:

Pellas, N., Fotaris, P., Kazanidis, I. \& Wells, D. (2017) Augmenting the learning experience in Primary and Secondary school education: A systematic review of recent trends in augmented reality game-based learning. Virtual Reality. Special issue: "Virtual and Augmented reality for enhanced experience in education and learning” (Springer).

DOI: https://doi.org/10.1007/s10055-018-0347-2 (to appear).

This material is presented to ensure timely dissemination of scholarly and technical work. Copyright and all rights therein are retained by authors or by other copyright holders. All persons copying this information are expected to adhere to the terms and constraints invoked by each author's copyright. In most cases, these works may not be reposted without the explicit permission of the copyright holder. 


\title{
Augmenting the learning experience in Primary and Secondary school education: A systematic review of recent trends in augmented reality game-based learning
}

\begin{abstract}
There is a significant body of research relating to augmented reality (AR) uses for learning in the Primary and the Secondary education sectors across the globe. However, there is not such a substantial amount of work exploring the combination of AR with game-based learning (ARGBL). Although ARGBL has the potential to enable new forms of teaching and transform the learning experience, it remains unclear how ARGBL applications can impact students' motivation, achievements, and learning performance. This study reports a systematic review of the literature on ARGBL approaches in compulsory education considering the advantages, disadvantages, instructional affordances and/or effectiveness of ARGBL across various Primary and Secondary education subjects. In total, 21 studies published between 2012 and 2017 in 11 indexed journals were analysed, with 14 studies focusing on Primary education and 7 on Secondary. The main findings from this review provide the current state of the art research in ARGBL in compulsory education. Trends and the vision towards the future are also discussed, as ARGBL can potentially influence the students' attendance, knowledge transfer, skill acquisition, hands-on digital experience, and positive attitude towards their learning. This review aims to lay the groundwork for educators, technology developers, and other stakeholders involved in the development of literacy programmes for young children by offering new insights with effective advice and suggestions on how to increase student motivation and improve learning outcomes and the learning experience by incorporating ARGBL into their teaching.
\end{abstract}

Keywords: Augmented reality, Game-based learning, Systematic review, Primary education, Secondary education

\section{Introduction}

\subsection{Game-based learning}

Technology and its associated media exert a continuously increasing influence on peoples' lives and existence. With this in mind, many children are benefiting from the use of digital tools on a daily basis. Video games are a clear example of a medium that young people are regularly engrossed in, e.g., almost 6 million 8 to 15 -year-olds play video games in the United Kingdom (IAB, 2014). Maintaining motivation and student engagement in the classroom is a challenge for teachers whose students may view their pedagogical choices and methods as dull and uninspiring (Hamari et al., 2016). Game-based learning (GBL) can help alleviate this disinterest and support motivational gain and engagement in the child's learning (Papastergiou, 2009). "Play" is a significant facet of GBL because through it people learn how to connect with and interpret their physical and social worlds (Gee, 2008). Additionally, games can be used as "bait" for learning, vehicles for content, architectures for engagement, and as "tools" to evaluate the users' strategies for gaining knowledge (Steinkuehler \& Squire, 2014). People who played games growing up obtain better educational qualification than those that did not. Additionally, they are greater consumers of culture (e.g., reading, painting, attending performing arts, and visiting heritage sites and libraries) and have a stronger tendency to engage in more active forms of cultural activity (Borowiecki \& Bakhshi, 2017).

Based on the above, researchers and game developers are trying to integrate educational content within gamebased contexts, with the goal to transform the educational process into a fun and engaging activity for learning. Various studies have considered the use of digital games as very important in supporting education, as students who were subjects to learning with video games reported significant improvements in subject understanding, diligence, and motivation (e.g., Fotaris et al., 2016; Prensky, 2008). Consequently, students in Primary and Secondary school education could be participating in lessons which reflect an emergent landscape that enables higher-order thinking skills (e.g., creativity, problem-solving, critical thinking, collaboration, information, and technology literacy) to be taught and secured from the beginning of a child's formal education (Pellas \& Vosinakis, 2018). This opportunity will help students understand and develop new knowledge, as well as build upon prior knowledge, which in turn will enable them to connect with the $21^{\text {st }}$ century's demands and needs.

The ever-increasing advancement in hardware and software along with the widespread use of mobile devices can provide the opportunity to rapidly increase students' learning participation through practical hands-on experiences (Fotaris et al., 2017). Consequently, the paradigm could shift away from lecture-style and more traditional teaching pedagogy towards active learning. Besides giving players the opportunity to learn through gameplay activities with clear goals, games also provide immediate feedback to the players' actions, which can have a positive effect on their performance (Pellas et al., 2016). 
Thence, the challenge is how games can be used in the classroom to produce deeper disciplinary learning and also support and guide the learner towards richer understanding and concept mastery (Papastergiou, 2009). Educators and scholars understand the importance of creativity and interaction in the learning process, so the use of interactive and innovative technologies can have a positive impact on the learning experience by allowing students to engage with topics in a personal and immersive way (Phipps et al., 2016).

\subsection{Augmented Reality in education}

As technology continues to advance at an extraordinary rate, Augmented Reality (AR) attracts a lot of attention (Fotaris et al., 2017). Azuma (1997) defines AR as a system or visualization technique that fulfills three main criteria: (a) a combination of real and virtual worlds; (b) real-time interaction; and (c) accurate 3D registration of virtual and real objects. AR layers simulate information on the physical environment, thus enabling the user to interact with virtual objects in the real world (Chen et al., 2016). AR applications are available through wireless and mobile devices such as smartphones, tablets, and smart glasses. They employ built-in cameras, Global Positioning System (GPS) sensors, accelerometers, solid state compasses, and Internet access to utilise either position data (location-aware AR) or real-world images and/or objects as visual markers that launch a digital information overlay (vision-based AR), thus embedding real-world environments with dynamic, context-aware, and interactive digital content (Chiang et al., 2014; Dunleavy \& Dede, 2014; Zhang et al., 2014).

By linking the physical world to the information browsing and delivery, AR can offer an intuitive way of giving contextual and location-specific information to the user (Alakärppä et al., 2017). It can also provide a landscape that enables children to engage with concepts that are not easily accessible in real life. Additionally, AR allows these difficult conceptions to be taught, and learners to solve complex problems, by combining real-time evidence from the natural world with virtual information (Muñoz et al., 2017; Chiang et al., 2014). AR is considered a realtime technology, as the physical environment is augmented by adding/embedding virtual information within it (Enyedy et al., 2012). This differs significantly from the notion of a Virtual Environment (or world), where the user is completely immersed in a synthetic environment (Bacca et al., 2014). In this sense, "AR supplements reality, rather than completely replacing it" (Azuma, 1997: 356) as it enriches the human senses with additional information beyond what is provided by the natural environment. Therefore, AR technology can provide an efficient understanding of abstract concepts, which can also lead to improved cognition and learning (Cai et al., 2016; Laine et al., 2016).

Mobile AR is regarded as one of the most promising technologies in the next ten years and it is easily accessible due to the high penetration of mobile phones (Alakärppä et al., 2017). International Data Corp. (IDC) projects that total spending on AR/VR products and services will soar from $\$ 9.1$ billion in 2017 to nearly $\$ 160$ billion in 2021, representing an annual growth rate of 113.2\% (IDC, 2017). Affordable AR systems are now available to the general public (Wu et al., 2013), while free mobile apps such as Blippar and HP Reveal allow users to create and share an overlaying digital content anchored to real-world objects (Blippar, 2018; HP Reveal, 2018). Additionally, the mainstream success of $\mathrm{AR}$ applications such as Pokémon $G O$, which has been reported to succeed in shifting human mobility patterns (Colley et al., 2017), has provided a means to explore this media within educational contexts (Atwood-Blaine \& Huffman, 2017). Furthermore, research evidence suggests that AR can increase student motivation in the learning process (Liu \& Chu, 2010; Bujak et al., 2013; Di Serio et al., 2013), promote "flow" (i.e., a user's state of "optimal experience") (Chang et al., 2014), and positively contribute to the overall learning experience (e.g., Chen et al., 2016; Tobar-Muñoz et al., 2017). Finally, the 2016 Horizon Report named AR a "soon-to-be adopted technology" for learning (Adams et al., 2016).

In addition to the above, the combination of AR with game-based learning (ARGBL) is quickly gaining momentum by enabling new approaches to teaching and learning experience in different Primary and Secondary school education scientific disciplines. The maturity and accessibility of AR technologies have prompted educators to harness the power of ARGBL in educational environments to create practical and highly interactive visual forms of learning (Huang et al., 2016; Furió et al., 2013; Hsiao et al., 2013). Applications capable of providing information on a specific object or location using visual markers are used in museums, art exhibitions, field studies (e.g., identification of plant species), and educational settings (Alakärppä et al., 2017; Sommerauer $\&$ Muller, 2014). Some of the most popular topics in Primary education that use AR for teaching are formal science (Atwood-Blaine \& Huffman, 2017; Hung et al., 2017; Hsiao et al., 2016; Laine et al., 2016), natural science (Chen et al., 2016; Chiang et al., 2014; Hwang et al., 2016; Furió et al., 2013;), physical science (Cai et al., 2016; Enyedy et al., 2012; Zhang et al., 2014), and social science (Chen \& Tsai, 2012; Efstathiou et al., 2017; Tobar-Muñoz et al., 2017). Likewise, in secondary education AR is also used to teach formal science (Echeverría et al., 2012), natural science (Hsiao et al., 2012; Kamarainen et al., 2013; Ruiz-Ariza et al., 2017), physical science (Bressler \& Bodzin, 2013; Cai et al., 2014), and social science (Di Serio et al., 2013). 


\section{Research rationale}

According to recent studies, content learnt through AR technologies can benefit students' long-term memory, problem-solving skills, enthusiasm, motivation, and collaborative abilities (Tobar-Muñoz et al., 2017; Hung et al., 2017; Alakärppä et al., 2017), as well as increase learning performance (Wei et al., 2015; Zhang et al., 2014), interaction and learning satisfaction (Huang et al., 2016; Hsiao et al., 2013). Still, there are researchers who suggest that using AR for educational purposes is still in its scarcity (Akçayır, M. \& Akçayır, G., 2017; Koutromanos et al., 2016; Wu et al., 2013). In scoping selected literature for this investigation, many AR studies appeared limited. Recent literature reviews, such as those by Chen et al. (2017) and Akçayır \& Akçayır (2017) only considered studies addressing the use of AR technology from K-12 to tertiary education which were published within Social Science Citation Index (SSCI) journals. Both these reviews suggest that the most reported advantage of AR is that it promotes enhanced learning achievement. Due to the limitations of these reviews though, additional research articles debating the educational impact of AR technologies can be identified through other databases, such as ERIC and ProQuest, or by analysing JCR-SCI Journals. When considering articles located in these supplementary databases, some researchers have noted challenges imposed by AR, including usability issues and frequent technical problems. In their study findings, Radu et al. (2014) pointed out that the positive impact of AR included increased content understanding, enhanced learning, improved language association, longterm memory retention, and enriched collaboration and motivation. However, they also claimed a need for further work to determine what types of content can be effectively taught using AR. Santos et al. (2014) based their review on previous studies published only in IEEE Xplore and applied a meta- and qualitative analysis in the dimensions of display metaphors, content creation, and evaluation techniques. In another review, Koutromanos et al. (2016) considered literature from 2000 to 2014 using the web databases of ScienceDirect and ERIC to identify the educational use of AR. The outcomes of their review illustrated a set of studies that give evidence of positive outcomes regarding student learning. The same authors provided some notable recommendations, including the need to exemplify the theoretical aspects and characteristics of design frameworks associated with learning through AR, as well as the pedagogical practice within which AR technology can be used.

However, what is clearly missing from the international literature are studies presenting and sufficiently analysing the educational potential and affordances of AR technology combined with GBL in educational settings (TobarMuñoz et al., 2017). AR and GBL are a natural assimilation, as AR offers the opportunity to participate in games using real-world learning objects (e.g., maps, books, and tools), thus adding a layer of play to the AR application (Tobar-Muñoz et al., 2017). AR games are also perceived to be more fun and engaging than basic mobile phone games, while they may also have a positive influence on the players' intentions to change behaviours (Juan et al., 2011). There is, therefore, a clear synergy here with AR which supports the notion that the combination of AR and GBL is worth exploring as an approach to learning.

Drawing upon the aforementioned assertions, this systematic review aims to investigate the potential use of ARGBL environments in Primary and Secondary education by summarising selected studies available in the relevant literature published from 2012 to 2017. The present study follows Wu et al.'s (2013) classifications of instructional approach usage. This decision was based on the fact that there are currently unexplored dimensions which focus on issues regarding the design and implementation of teaching and learning methods using AR technologies. In addition, the review by Palmarini et al. (2018) points out the need for correlation between AR technologies and their applications in a more systematic way. Furthermore, the exploration will also consider pedagogy suitable for the classroom and extended school learning environments, thus extending the roadmap for further research. Specifically, the goals of this study are as follows:

a. To provide an overview of the educational use of ARGBL in Primary and Secondary education, including the kinds of devices used, the digital resources and employed software, what subjects are making use of AR technology, where courses using AR take place, and how the devices are used for teaching and learning.

b. To present the overall effect on students' learning achievements when ARGBL is integrated into Primary and Secondary education.

c. To synthesise the potential teaching and learning advantages and disadvantages of implementing ARGBL within different instructional contexts, based on analysis of relevant articles.

The current systematic review serves as a useful and timely addition to the existing literature examining the combination of AR technology and game-based learning within compulsory education. The results of this investigation may offer new insights to researchers and provide educators with inspiration, effective advice, and suggestions on how to incorporate an ARGBL model into their teaching. The reviewed articles suggested that ARGBL applications have clear potential to positively influence students' attendance, engagement, knowledge transfer, skill acquisition, hands-on digital experience, and attitude towards their learning. 
Since AR is an emerging technology, it is important to provide an overview of the advances and impact of its use in playful and game-orientated educational settings. Within this context, the research questions addressed by this study are as follows:

RQ1: What are the main game-based learning approaches that students have participated in, with the purpose of improving their learning outcomes?

RQ2: What AR-enabled devices have been used to enhance the game-based learning experience, and in what instructional conditions has this experience taken place?

RQ3: What are the potential benefits and limitations regarding the learning effectiveness of combining AR with game-based applications in Primary and Secondary education?

\section{Methodology}

The guidelines proposed by Kitchenham (2007) were adapted for the purposes of this systematic review using the following steps:

Step 1: Planning: (a) Selection of journals, (b) Definition of inclusion and exclusion criteria for studies,

(c) Definition of categories for the analysis.

Step 2: Conducting the review: (a) Study selection, (b) Data extraction (content analysis methods were applied), (c) Data synthesis, (d) Data coding.

Step 3: Reporting the review: Analysis of the results and discussion of the findings, trends and conclusions regarding the "Preferred Reporting Items for Systematic Reviews and Meta-Analyses (PRISMA)" statement (Moher et al., 2009).

To further understand the adopted method choices, the following can be considered:

Step 1(a): Selection of journals

In this initial step, it was imperative to choose the most relevant journals, i.e., journals that are methodologically strong and scientifically relevant. The Google Scholar h5-index for the category "Educational Technology" was used as a starting point, since this category is more precise than the "Education and Educational Research" category from the Journal Citation Report Social Science Citation Index (JCR SSCI). In the latter, most of the journals relating to educational technology are indexed together with journals about educational research in general, offering too broad a foundation from which to start the literature search. To review studies of potentially more consistent quality, a list produced from the top journals from the "Educational Technology" category according to the Google Scholar h5-index was initially validated through an iterative double-check process. This feature is defined in the JCR by considering the citation relationship of the journals and is based on the number of citations from one journal to the other and the total number of articles.

The present review also considered the Journal Citation Reports Science Citation Index Expanded (JCR SCI), and the same process with the iterative double check for the JCR SSCI journal was repeated. All international journals, whose articles were accepted in this review, have impact factors ranging from 0.576 to 3.819 according to 2016 data metrics as defined by Thomson Reuters Journal Citation Reports (2017). The fact that important journals within their field publish articles on ARGBL is an indication that this emerging approach to learning is of great interest to researchers and educators who aspire to enrich their students' experience.

To study the educational potential of the reviewed studies the following categories should be identified:

a. instructional design methods or models based on theoretical foundations, and research methodologies that measured the successful implementation of learning objectives using AR applications.

b. the purpose of these studies and their scientific construction and understanding of knowledge.

c. the effect and/or effectiveness the AR technology had on student engagement following different teaching approaches.

d. the learning gain in different educational subjects.

e. the students' performance and the impact of using AR with game-based conditions on their learning outcomes.

For quality purposes, preference was given to papers which used qualitative and/or quantitative analysis of results, as these are considered the most accurate forms of experimental research to prove or disprove a hypothesis (Punch, 1998). For an experiment to be classified as a valid experimental design, the following criteria must be fulfilled (Russell \& Gregory, 2003):

a. The research question should be clearly defined and adequately substantiated. 
b. The method of sampling should be appropriate for the research questions and instructional design methods.

c. The data must be analysed appropriately.

d. The analytical description of findings should be provided either with qualitative or quantitative data.

e. The meaning or relevance of the study should have some practical implications for knowledge acquisition.

The selected reviewed papers for qualitative analysis were chosen as having purposeful sampling based on a conscious selection of a small number of data sources. They also evidenced the logical reasoning and power of purposeful sampling in selecting information-rich cases (participants or settings) leading to an in-depth study that illuminates the questions of interest, covering a wide range of potentially relevant social phenomena and perspectives. Finally, they provided a descriptive analysis of methods exploring new cases or perspectives, which may lead to future-driven uses of ARGBL.

\section{Data analysis}

\section{Coding of papers}

The twenty-one $(\mathrm{n}=21)$ articles meeting the inclusion criteria of this review were coded after considering previous studies (Ackyar M. \& Ackyar, G., 2017; Koutromanos et al., 2016), which categorised games and their outcomes and impacts in relation to several dimensions.

\section{Categorisation of games}

Games were categorised according to the following:

a. The aim of the game and whether it was originally designed to combine entertainment with learning.

b. The learning subject/topic that each game addressed, e.g., science, maths, language, etc.

c. The platform/computing devices that users played the game on, e.g., video consoles, personal computers, smartphones, tablets, etc.

The categorisation of the ARGBL effect

The current study focused on the positive impact of ARGBL on the learning experience. The categories used to analyse this impact were as follows:

a. Learning outcomes relating to ARGBL, which resulted in knowledge acquisition or content understanding of specific learning subjects, skill gaining, and achievements.

b. Assessment processes for specific subjects or other measurements of psychological issues, which affected students' outcomes, performance, and achievements in specific learning objectives.

c. The effect of ARGBL is examined regarding the learning subjects' scope in playing and using a specific game.

\section{Coding of methods}

The articles that have been included in the present systematic review were coded based on the following methodological dimensions:

a. Study design and type of used methodology (quantitative, qualitative or mixed). The design of each study was further coded according to whether it used a true experimental design, a quasi-experimental design, a comparative study or a qualitative research design;

b. Data collection and analysis: studies were coded according to the methods used to collect data and the reliability and validity of these data collection tools;

c. Results and conclusions presented a summary of the most significant findings from each study.

\section{Quality of the studies}

Every reviewed paper was read and was selected for inclusion in the study based on the following criteria:

1. The appropriateness of the research design for addressing the question/sub-questions of this review (with a higher weighting for the inclusion of a control group).

2. The appropriateness of both the research methods and the analysis of the study results.

3. The adequacy of each one of the study's research questions.

4. The alignment of the study findings with the research question(s).

The total weight of evidence for each paper was calculated by adding the scores on each of the aforementioned criteria. 


\section{Inter-rater reliability}

To assess inter-rater reliability with respect to the quality coding of the papers, a sub-sample of 7 of the 21 papers (33.3\%) was coded independently by two of the review's authors. The inter-rater reliability ( $r$ ) for the total scores was 0.89 , showing good agreement between the two authors for the quality of the selected papers.

Search strategy and development of a search protocol

The electronic databases which were searched in this review included those identified as relevant to education, information technology, and social science. These searched databases were from SCOPUS, ScienceDirect, ESCBO, JSTOR, ERIC, Web of Science, and Wiley (see Appendix). Web searches were conducted using Google Scholar as a search engine. Branching searches were performed using forward and backward search procedures from the reference lists of previous literature reviews that were consulted at earlier stages of this study (e.g., Ackyar M. \& Ackyar, G., 2017; Chen et al., 2017; Koutromanos et al., 2016).

\section{Search terms}

The search terms (keywords) that were used for the purposes of this study included terms for games in conjunction with terms for possible outcomes, impacts or effects of playing games for learning. Several search terms helped the authors to determine the scope of the definition of digital games since many of the terms include the word "game" such as "computer game”, "video game”, "simulation game” and "game-based learning”. More specific terms were also included such as "Augmented Reality Game-based", "Augmented Reality games" and "AR", along with terms about learning, e.g., "learning” and "education". The table in the Appendix shows the search protocol that was followed for each database.

Step 1(b): Inclusion and exclusion criteria

In regard to the research questions, the following general criteria, which defined the time frame and the type of relevant studies, were agreed upon:

General Criteria:

a. Studies published between 2012 and 2017.

b. Studies describing applications or frameworks for ARGBL in Primary and Secondary education.

c. Conceptual articles or studies that provided evidence of educational potential based upon a research method.

d. Articles whose abstract and full-paper were written in English.

Specific Criteria:

a. Studies reporting the advantages, disadvantages, instructional affordances and/or effectiveness of ARGBL across various Primary and Secondary education subjects.

b. Studies describing applications that considered user models and/or adaptive processes combined with ARGBL.

c. Studies describing applications of ARGBL in Primary and Secondary education for students in the context of diversity.

d. Studies presenting evaluation methods for ARGBL in various educational scenarios.

\section{Exclusion Criteria:}

a. Studies not identified as "articles" in the selected journals (e.g., books, book reviews/chapters, colloquiums, editorial publication information, etc.).

b. Studies that either mentioned the term " $A R$ ” but were on an unrelated topic to game-based learning or mentioned the term "game-based learning" but were on an unrelated topic to AR.

c. Studies that did not provide sufficient data for effect size calculation or did not have clear summarisation or aggregative findings from their qualitative data.

d. Articles that did not present data from evaluations or did not follow well-structured research methods (case studies, empirical etc.)

e. Articles that were not written in English.

f. Articles published before 2007 or after the third quarter of 2017.

g. Studies that focused on the use of Mixed or Virtual Reality instead of AR.

Step 1(c): Categories for analysis and data coding: In this stage, a group of analysis categories were defined for each research question. This categorisation assisted the grouping of all relevant studies based on their shared characteristics. During the systematic review process, some sub-categories emerged, and others were refined to cover all relevant information. The list of categories for the analysis informed by the research questions is as follows: 
RQ1: What are the main game-based learning approaches that students participated in with the purpose of improving their learning outcomes?

This review considers the type of game-based approaches, instructional methods, forms of assessment, and types of user modelling that were used in each study.

RQ2: What AR-enabled devices have been used to enhance the game-based learning experience, and in what instructional conditions have this experience taken place?

This review considers the type of devices used (e.g., tablets, smartphones, PCs, wearable devices) and the environments where each study took place (e.g., in-class, during field trips, outdoors, etc.)

RQ3: What are the potential benefits and limitations regarding the learning effectiveness of AR with game-based applications in Primary and Secondary education?

This review places importance on the reported purposes, learning topics, advantages or limitations on student performance and learning gain, and the negative perceptions of using AR across different devices.

The content analysis allowed research trends of a topic to be identified by grouping papers together according to their shared characteristics. The studies were manually coded separately according to their key characteristics and were classified according to the categories and sub-categories defined above.

\section{Analysis of relevant literature}

Table 1 presents 10 journals associated with the JCR-SSCI list that contained a total of 14 articles selected for this study, which discussed game-based learning with AR technologies in Primary education. Similarly, Table 2 presents 4 journals which contained a total of 7 articles discussing ARGBL in Secondary education. While the number of articles may appear limited, an analysis of the publication year of each article shows that the number of published studies relating to ARGBL in Primary and Secondary education has progressively increased yearby-year, particularly during the last two years. These results make clear that ARGBL in education is an emerging topic, corroborating the opinions of previous studies (Chen \& Tsai, 2012; Wu et al., 2013), who pointed out that research into ARGBL in education is still in its early stages.

Table 1. Number of ARGBL studies for Primary education published in international journals (2012-2017)

\begin{tabular}{|c|c|c|c|}
\hline & JCR-SSCI Journal (Publishers) & $\begin{array}{c}\text { Analysed studies } \\
(\mathbf{2 0 1 2 - 2 0 1 7 )}\end{array}$ & $\begin{array}{c}\text { Impact } \\
\text { Factor }(\mathbf{2 0 1 6}) \\
\end{array}$ \\
\hline 1. & Computers \& Education (Elsevier) & 3 & 3.819 \\
\hline 2. & Interactive Learning Environments (Taylor \& Francis) & 3 & 1.674 \\
\hline 3. & Journal of Computer Assisted Learning (Wiley) & 1 & 1.253 \\
\hline 4. & Journal of Educational Computing Research (SAGE) & 1 & 1.179 \\
\hline 5. & $\begin{array}{l}\text { International Journal of Computer-Supported Collaborative } \\
\text { Learning (Springer) }\end{array}$ & 1 & 3.469 \\
\hline 6. & $\begin{array}{l}\text { Educational Technology Research and Development } \\
\text { (Springer) }\end{array}$ & 1 & 0.725 \\
\hline 7. & Journal of Science Education and Technology (Springer) & 1 & 1.080 \\
\hline 8. & The Asia-Pacific Education Researcher (Springer) & 1 & 0.576 \\
\hline 9. & $\begin{array}{l}\text { International Journal of Science and Mathematics Education } \\
\text { (Springer) }\end{array}$ & 1 & 1.474 \\
\hline 10. & Journal of Educational Technology \& Society (Online) & 1 & 1.584 \\
\hline \multicolumn{4}{|c|}{ Table 2. Number of ARGBL studies for Secondary education published in international journals (2012-2017) } \\
\hline & JCR-SSCI Journal (Publishers) & $\begin{array}{c}\text { Analysed studies } \\
(2012-2017)\end{array}$ & $\begin{array}{c}\text { Impact Factor } \\
(2016) \\
\end{array}$ \\
\hline 1. & Computers \& Education (Elsevier) & 3 & 3.819 \\
\hline 2. & Computers in Human Behavior (Elsevier) & 2 & 3.435 \\
\hline 3. & Interactive Learning Environments (Taylor \& Francis) & 1 & 1.674 \\
\hline 4. & Journal of Computer Assisted Learning (Wiley) & 1 & 1.253 \\
\hline
\end{tabular}

The coding scheme of the reviewed papers

A coding scheme with the main criteria for each article is provided. The latter are as follows: 
a. The instructional design method that was implemented.

b. The characteristics of the AR technologies that were used.

c. The theoretical underpinnings (based on contemporary learning theories) that were followed.

d. The instructional design format that was used to improve the learning experience.

Figure 1 presents a flowchart of the article selection process that was followed using guidelines from Liberati et al. (2009).

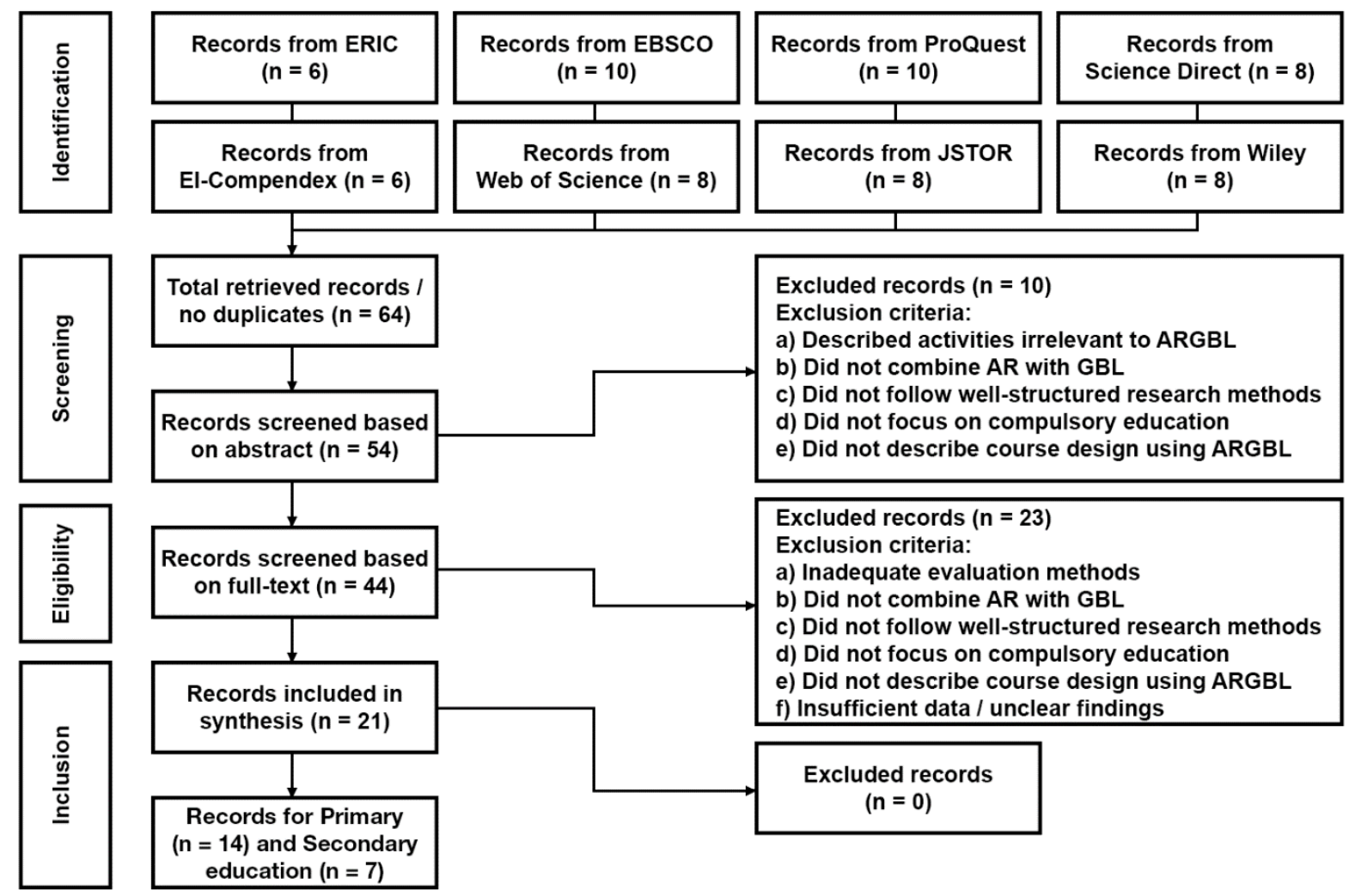

Figure 1. Flowchart for article selection process associated with publications of ARGBL in Primary and Secondary education

The first author of this study conducted all the content analysis results. The data was validated by the other three authors who are experienced researchers in Informatics and Education. They conducted the screening tasks and discussed with the first author the overall decisions based on the prescribed selection rules. All authors read the full text of each article, following the coding scheme of Figure 2, in order to decide if it could be included in this review. 


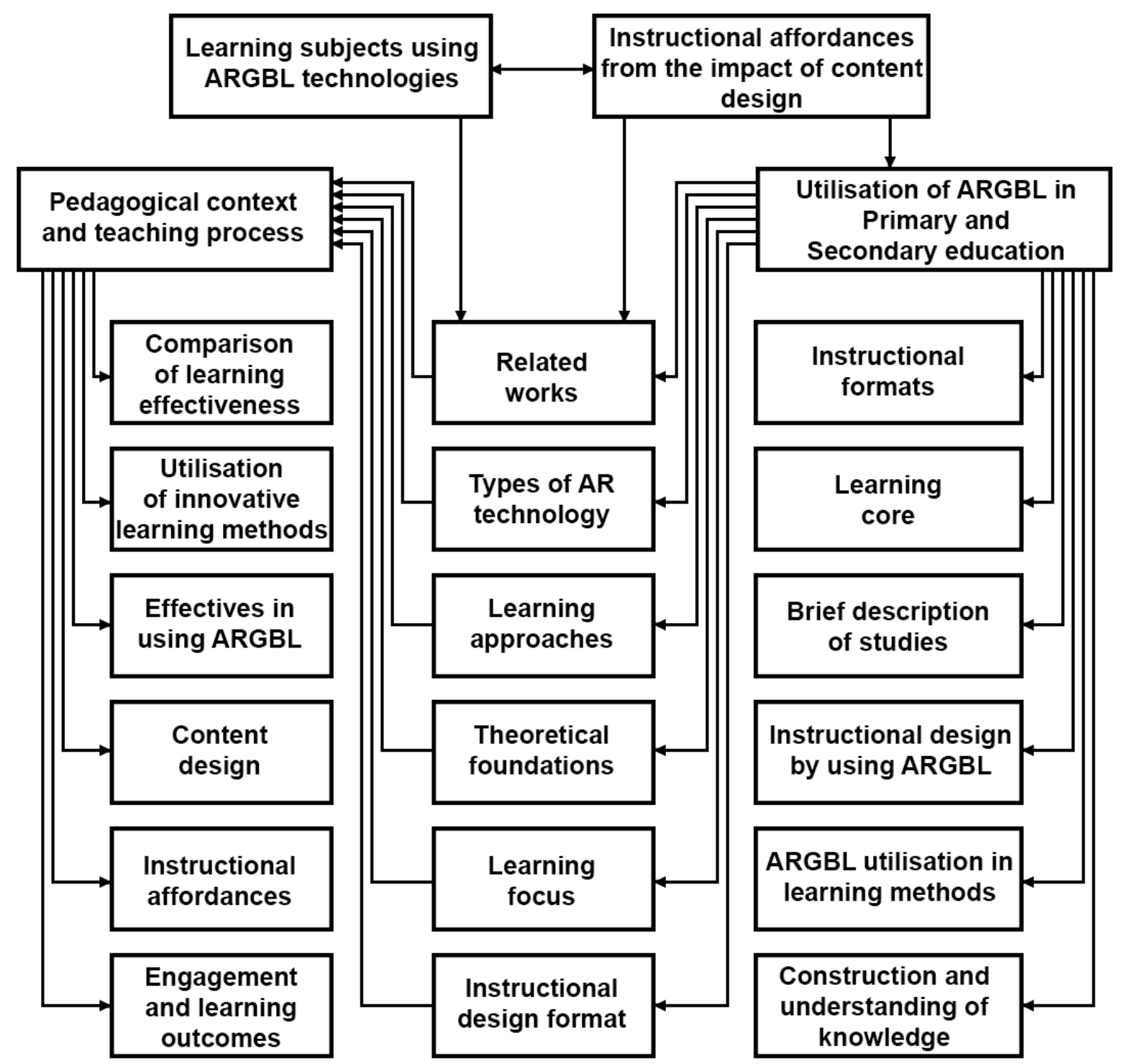

Figure 2. The coding scheme of the reviewed papers

Data collection and content analysis tool

Nvivo (ver. 10) software was used to perform a content analysis of the reviewed studies in order to process and analyse the data and assess the reliability of the results.

\section{Results}

This section describes and discusses the results of the conducted review. In Step 2(a), as described in the Methodology section, a manual search was conducted in the selected journals. The inclusion and exclusion criteria were applied to select the studies for the review, leading to a selection of 21 journal studies in total. Step 2(b) and Step 2(c) were carried out by reading the papers thoroughly. The data coding process was performed according to the categories defined in step $1(c)$. The results were presented in line with the research questions.

As the research methods used for instructional design methods, research and data collection differed so greatly, it was not possible to undertake an accurate meta-analysis. The overall results were synthesised to extract the main themes under which the findings of the review are identified and presented. As the process was inductive, there were no initial themes assigned to the data. A synopsis of the game-based instructional and learning approaches, as well as the results and most crucial observations for each reviewed study, appear in Tables 3 (Primary education) and 4 (Secondary education), respectively. 
Table 3. A general overview of ARGBL studies in Primary education

\begin{tabular}{|c|c|c|}
\hline $\begin{array}{l}\text { Research } \\
\text { studies }\end{array}$ & $\begin{array}{l}\text { Game-based instructional and learning } \\
\text { approaches }\end{array}$ & Study results and observations \\
\hline \multirow{2}{*}{$\begin{array}{l}\text { Atwood- } \\
\text { Blaine \& } \\
\text { Huffman } \\
\text { (2017) }\end{array}$} & \multirow[t]{2}{*}{$\begin{array}{l}\text { Location-based ARGBL during a field } \\
\text { trip to a science centre. }\end{array}$} & $\begin{array}{l}\text { Female students outperformed male on every measure of the } \\
\text { iPad game achievement. }\end{array}$ \\
\hline & & $\begin{array}{l}\text { Females were more goal-oriented, persistent in the face of } \\
\text { difficulty, and appreciative of the collaborative challenge, } \\
\text { while males enjoyed the fun and competitive aspect. }\end{array}$ \\
\hline $\begin{array}{l}\text { Efstathiou et } \\
\text { al. }(2017)\end{array}$ & $\begin{array}{l}\text { Inquiry-based learning using a location- } \\
\text { based AR game during a field trip to an } \\
\text { archaeological site. }\end{array}$ & $\begin{array}{l}\text { Students who employed the AR application outperformed the } \\
\text { students of the traditional field trip. }\end{array}$ \\
\hline $\begin{array}{l}\text { Hung et al. } \\
\text { (2017) }\end{array}$ & $\begin{array}{l}\text { Digital game-based learning and an AR } \\
\text { educational book. }\end{array}$ & $\begin{array}{l}\text { AR improved students' learning performances to a similar } \\
\text { extent as conventional teaching material, such as picture } \\
\text { books and physical interactions. }\end{array}$ \\
\hline $\begin{array}{l}\text { Tobar- } \\
\text { Muñoz et al. } \\
(2017)\end{array}$ & $\begin{array}{l}\text { ARGBL in a naturalistic environment } \\
\text { using AR to promote reading } \\
\text { comprehension. }\end{array}$ & $\begin{array}{l}\text { Increased motivation and interest in problem-solving, } \\
\text { exploration, and socialisation behaviour. }\end{array}$ \\
\hline \multirow{2}{*}{$\begin{array}{l}\text { Cai et al. } \\
(2016)\end{array}$} & \multirow{2}{*}{$\begin{array}{l}\text { Team-based inquiry-based learning in a } \\
\text { problem-based explorative mode with AR } \\
\text { motion-sensing learning technology. }\end{array}$} & A better understanding of magnetic fields. \\
\hline & & $\begin{array}{l}\text { Increased motivation and interest which encouraged students } \\
\text { to learn more actively and extensively. }\end{array}$ \\
\hline \multirow[t]{2}{*}{$\begin{array}{l}\text { Chen et al. } \\
(2016)\end{array}$} & $\begin{array}{l}\text { A Concept Mapped AR Learning system } \\
\text { (which used a concept map as its learning } \\
\text { structure); }\end{array}$ & \multirow[t]{2}{*}{$\begin{array}{l}\text { Students achieved better learning outcomes, increased their } \\
\text { learning motivation and improved their learning attitudes. }\end{array}$} \\
\hline & $\begin{array}{l}\text { Standard AR Learning system (which } \\
\text { used a book as its learning structure). }\end{array}$ & \\
\hline $\begin{array}{l}\text { Hwang et al. } \\
\text { (2016) }\end{array}$ & $\begin{array}{l}\text { Location-based ARGBL during a field } \\
\text { trip to a butterfly garden. }\end{array}$ & $\begin{array}{l}\text { The ARGBL approach improved both the students' learning } \\
\text { attitudes and their learning performance at the field trip. }\end{array}$ \\
\hline \multirow{2}{*}{$\begin{array}{l}\text { Laine et al. } \\
\text { (2016) }\end{array}$} & \multirow{2}{*}{$\begin{array}{l}\text { Context-aware storytelling and science } \\
\text { learning games. }\end{array}$} & Students appreciated geometry following ARGBL input. \\
\hline & & $\begin{array}{l}\text { The game has the potential for affecting the players' attitudes } \\
\text { towards mathematics. }\end{array}$ \\
\hline $\begin{array}{l}\text { Chiang et al. } \\
(2014)\end{array}$ & $\begin{array}{l}\text { Inquiry-based mobile learning approach } \\
\text { compared to AR-based mobile learning } \\
\text { approach. }\end{array}$ & $\begin{array}{l}\text { Better learning achievements and significantly higher } \\
\text { motivations relating to attention, confidence, and relevance } \\
\text { for students who followed the AR-based mobile learning } \\
\text { approach. }\end{array}$ \\
\hline \multirow[t]{2}{*}{$\begin{array}{l}\text { Zhang et al. } \\
(2014)\end{array}$} & \multirow[t]{2}{*}{$\begin{array}{l}\text { Interactive learning in an outdoor/indoor } \\
\text { location using a mobile AR astronomy } \\
\text { simulation software. }\end{array}$} & $\begin{array}{l}\text { MDAS system enhanced students' learning of astronomical } \\
\text { observation content and their performance of astronomical } \\
\text { observation skills. }\end{array}$ \\
\hline & & $\begin{array}{l}\text { Increased student interest in astronomical observations and } \\
\text { learning, which had a substantial effect on retention. }\end{array}$ \\
\hline \multirow[t]{2}{*}{$\begin{array}{l}\text { Furió et al. } \\
\text { (2013) }\end{array}$} & \multirow{2}{*}{$\begin{array}{l}\text { Mobile game using multiple interaction } \\
\text { forms (touch-screen interaction, } \\
\text { accelerometer) and a combination of AR } \\
\text { with non-AR mini-games. }\end{array}$} & $\begin{array}{l}\text { Students showed significant learning gains after the } \\
\text { intervention. }\end{array}$ \\
\hline & & $\begin{array}{l}\text { Weight and size of the device do not have an impact on } \\
\text { learning outcomes, satisfaction, engagement, interaction, and } \\
\text { AR experience. }\end{array}$ \\
\hline $\begin{array}{l}\text { Hsiao et al. } \\
(2013)\end{array}$ & $\begin{array}{l}\text { Inquiry-based learning through a } \\
\text { manipulative AR system. }\end{array}$ & $\begin{array}{l}\text { Greater positive impact on the students' academic } \\
\text { achievement, satisfaction and motivation compared to the use } \\
\text { of multimedia teaching resources installed on a tablet. }\end{array}$ \\
\hline \multirow[t]{2}{*}{$\begin{array}{l}\text { Chen \& Tsai } \\
(2012)\end{array}$} & \multirow{2}{*}{$\begin{array}{l}\text { Digital game-based learning using an } \\
\text { educational AR system based on situated } \\
\text { learning theory to enhance library } \\
\text { instruction. }\end{array}$} & $\begin{array}{l}\text { Learning performance of students provided more benefits in } \\
\text { terms of library skills of application and comprehension. }\end{array}$ \\
\hline & & $\begin{array}{l}\text { Students' gender or gaming skills do not affect learning } \\
\text { performance. }\end{array}$ \\
\hline $\begin{array}{l}\text { Enyedy et al. } \\
(2012)\end{array}$ & $\begin{array}{l}\text { Computer-supported collaborative } \\
\text { learning for physics through Play Project } \\
\text { (LPP). }\end{array}$ & $\begin{array}{l}\text { Students developed a better conceptual understanding of } \\
\text { force, net force, friction and two-dimensional motion after } \\
\text { participating in the LPP curriculum. }\end{array}$ \\
\hline
\end{tabular}


Table 4. A general overview of ARGBL studies in Secondary education

\begin{tabular}{|c|c|c|}
\hline $\begin{array}{l}\text { Research } \\
\text { studies }\end{array}$ & $\begin{array}{l}\text { Game-based instructional and } \\
\text { learning approaches }\end{array}$ & Study results and observations \\
\hline $\begin{array}{l}\text { Ruiz-Ariza et } \\
\text { al. (2017) }\end{array}$ & $\begin{array}{l}\text { Location-based ARGBL (Pokémon } \\
G O) \text { using Smartphone GPS }\end{array}$ & $\begin{array}{l}\text { Pokémon } G O \text { significantly increased players' selective } \\
\text { attention, concentration levels, and sociability levels; } \\
\text { Pokémon } G O \text { could be used from schools and families to raise } \\
\text { daily physical activity. }\end{array}$ \\
\hline $\begin{array}{l}\text { Cai et al. } \\
(2014)\end{array}$ & $\begin{array}{l}\text { Inquiry-based experiments using } \\
\text { marker-based AR to control, } \\
\text { combine and interact with a 3D } \\
\text { model of micro-particles. }\end{array}$ & $\begin{array}{l}\text { AR tools can be used as supplemental learning material. } \\
\text { AR tools are more effective for low-achieving students. } \\
\text { Students' learning attitudes are positively correlated with their } \\
\text { evaluation of the software. }\end{array}$ \\
\hline $\begin{array}{l}r \& \\
(2013)\end{array}$ & $\begin{array}{l}\text { science mystery game } \\
\text { on mobile devices }\end{array}$ & $\begin{array}{l}\text { Students' flow experience features included a flash of intensity, } \\
\text { a sense of discovery and the desire for higher performance. } \\
\text { Potential for mobile AR science games to increase science } \\
\text { interest and improve collaboration skills. }\end{array}$ \\
\hline $\begin{array}{l}\text { Kama } \\
\text { al. }(2\end{array}$ & $\begin{array}{l}\text { Location-based AR inquiry-based } \\
\text { learning during a field trip to a local } \\
\text { pond environment. }\end{array}$ & $\begin{array}{l}\text { Positive effect on students' motivation and engagement during } \\
\text { the AR learning experience. } \\
\text { Students achieved a better learning gain. }\end{array}$ \\
\hline $\begin{array}{l}\text { Di Serio } \\
(2013)\end{array}$ & $\begin{array}{l}\text { Study of Renaissance art } \\
\text { masterpieces through the } \\
\text { presentation of their images and } \\
\text { explanation of their relevant details } \\
\text { with AR using Popcode or slides. }\end{array}$ & $\begin{array}{l}\text { Motivational factors of attention and satisfaction in ARGBL } \\
\text { were better rated than those of a slides-based environment. } \\
\text { Attention and confidence factors were best rated when the } \\
\text { impact of the AR system was analysed in isolation. }\end{array}$ \\
\hline $\begin{array}{l}\text { Echeverría et } \\
\text { al. (2012) }\end{array}$ & $\begin{array}{l}\text { Co-located collaborative games in } \\
\text { the classroom using AR and } \\
\text { multiple-mice technology to teach } \\
\text { electrostatics. }\end{array}$ & $\begin{array}{l}\text { Students significantly increased their conceptual understanding } \\
\text { of electrostatics with both platforms. } \\
\text { AR version of the game was considerably costlier to deploy. } \\
\text { Boys performed significantly better than girls. }\end{array}$ \\
\hline $\begin{array}{l}\text { Hsiao et al. } \\
(2012)\end{array}$ & $\begin{array}{l}\text { Ecosystems AR Learning System } \\
\text { (EARLS) with "Learning" (AR- } \\
\text { enhanced text books) and "Games" } \\
\text { (stimulates interaction through } \\
\text { learners' body movements to } \\
\text { increase physical exercise) sections. }\end{array}$ & $\begin{array}{l}\text { Learning while exercising is equally effective with EARLS, } \\
\text { keyboard/mouse-based computer-assisted instruction and } \\
\text { traditional learning. } \\
\text { EARLS users earned extra exercise without diminishing the } \\
\text { quality of learning achievement, were more interested and } \\
\text { motivated, and showed less anxiety. }\end{array}$ \\
\hline
\end{tabular}

As shown in Table 5 below, an interesting result that emerged from the data is that the majority of the studies were applied to Science, Technology, Engineering, and Mathematics (STEM) subjects. More specifically, 28.6\% of ARGBL experiences in Primary education covered formal science topics (Atwood-Blaine \& Huffman, 2017; Hung et al., 2017; Laine et al., 2016; Hsiao et al., 2013), 28.6\% were about natural science (Chen et al., 2016; Hwang et al., 2016; Chiang et al., 2014; Furió et al., 2013), 21.4\% about physical science (Cai et al.,2016; Zhang et al., 2014; Enyedy et al., 2012), and 21.4\% covered social science topics (Chen \& Tsai, 2012; Efstathiou et al., 2017; TobarMuñoz et al., 2017).

Likewise, $42.8 \%$ of ARGBL approaches in Secondary education employed ARGBL to enhance instructional settings of natural science topics (Hsiao et al., 2012; Kamarainen et al., 2013; Ruiz-Ariza et al., 2017), 28.6\% covered physical science (Cai et al., 2014; Bressler \& Bodzin, 2013), 14.3\% were about formal science (Echeverría et al., 2012), and $14.3 \%$ addressed social science topics (Di Serio et al., 2013).

Table 5. ARGBL uses according to academic discipline

\begin{tabular}{lcc}
\hline Primary education & Number of studies & Percentage (\%) \\
\hline Formal Science & 4 & 28.6 \\
Natural Science & 4 & 28.6 \\
Physical Science & 3 & 21.4 \\
Social Science & 3 & 21.4 \\
\hline Secondary education & Number of studies & Percentage (\%) \\
\hline Formal Science & 1 & 14.3 \\
Natural Science & 3 & 42.8 \\
Physical Science & 2 & 28.6 \\
Social Science & 1 & 14.3 \\
\hline
\end{tabular}


A possible explanation to why ARGBL seems more suitable for teaching Science and other STEM subjects might be the fact that it offers the ability to bring to life invisible, abstract, and complex concepts. Students do not have to rely only on their imagination to envision what is happening (Bacca et al., 2014), because AR can augment the physical world by computer-generated perceptual information and integrate immersive sensations that are perceived as natural parts of the real-world environment.

Table 6 shows the research methods that were applied to the reviewed studies. A crucial observation is that several studies used medium-sized research samples (between 30 and 200 participants) and employed mixed methods to collect quantitative and qualitative data. The most prevalent data collection methods were questionnaires, interviews, and surveys. More specifically, in Primary education 8 studies $(57.1 \%)$ followed mixed research methods and presented results from quantitative and qualitative data (Efstathiou et al., 2017; Hung et al., 2017; Cai et al., 2016; Hsiao et al., 2013; Hwang et al., 2016; Laine et al., 2016; Furió et al., 2013; Enyedy et al., 2012;); 4 used quasi-experimental studies (Atwood-Blaine \& Huffman, 2017; Chen et al., 2016; Tobar-Munoz et al., 2017; Zhang et al., 2014), and two (14.3\%) presented quantitative data based on experimental-comparative methods (Chiang et al., 2014; Chen \& Tsai, 2012).

Likewise, 4 studies (Cai et al., 2014; Di Serio et al., 2013; Echeverría et al., 2012; Ruiz-Ariza et al., 2017) in Secondary education presented quantitative data from an experimental-comparative study (57.1\%). Also, 3 studies (Bressler \& Bozin, 2013; Hsiao et al., 2012; Kamarainen et al., 2013) used mixed methods research designs $(42.9 \%)$, while no study followed a quasi-experimental approach.

Table 6. Research methods applied

\begin{tabular}{lcc}
\hline Primary education & Number of studies & Percentage (\%) \\
\hline Experimental-comparative method & 2 & 14.3 \\
Quasi-experimental & 4 & 28.6 \\
Mixed methods & 8 & 57.1 \\
\hline Secondary education & Number of studies & Percentage (\%) \\
\hline Experimental-comparative method & 4 & 57.1 \\
Quasi-experimental & 0 & 0.0 \\
Mixed methods & 3 & 42.9 \\
\hline
\end{tabular}

Table 7 displays the study results with respect to the category "Effectiveness of $A R$ ". Since a single study can report more than one sub-category of effectiveness, each study can also fulfill more than one sub-category. The majority of Primary education studies (50\%) reported that AR applications combined with game-based learning led to "better learning performance and/or learning gains" in educational settings. Additionally, $21.4 \%$ of studies suggest increases in "student motivation and engagement", and $14.3 \%$ articulate improvements in both "students" positive perception and attitudes" and "student interaction/socialisation / collaboration". Similar findings came from Secondary education, with $57.1 \%$ of studies reporting "better learning performance and/or learning gains". $28.6 \%$ identifying an increase in "student motivation and engagement", $14.3 \%$ an increase in "students' positive attitudes", and $14.3 \%$ an increase in "student interaction / socialisation / collaboration".

Table 7. The effectiveness of using ARGBL in compulsory educational settings

\begin{tabular}{lcc}
\hline Primary education & Number of studies & Percentage (\%) \\
\hline Better learning performance and/or learning gains & 7 & 50.0 \\
Student motivation and engagement & 3 & 21.4 \\
Students' positive perceptions and attitudes & 2 & 14.3 \\
Student interaction / socialisation / collaboration & 2 & 14.3 \\
\hline Secondary education & Number of studies & Percentage (\%) \\
\hline Better learning performance and/or learning gains & 4 & 57.1 \\
Student motivation and engagement & 2 & 28.6 \\
Students' positive perceptions and attitudes & 1 & 14.3 \\
Student interaction / socialisation / collaboration & 1 & 14.3 \\
\hline
\end{tabular}

This review considered three types of AR according to the classification from Chen and Tsai (2012): marker-based, markerless, and location-based. Marker-based AR (also called Image Recognition) uses a camera and some type of visual marker that triggers an event when sensed by a reader (e.g., display a 3D image spatially aligned with the marker's position). Typical markers include a QR/2D code or labels containing a coloured or black and white pattern that is easily recognised or registered by the AR application. Markerless AR uses sensors in devices to accurately detect the real-world environment, such as the locations of walls and points of intersections, allowing users to place virtual objects into a real context without needing to read an image. Finally, location-based AR uses 
a GPS, digital compass, velocity meter, or accelerometer which is embedded in the device to provide data based on the user's geographical location.

Results in Table 8 reveal that the majority of the reviewed studies used marker-based AR (50\% in Primary and $75 \%$ in Secondary education), thus indicating that most AR educational applications are likely to use markers. A possible explanation might be that the tracking process of markers is more effective and more stable compared to the markerless tracking techniques currently available. Implementation of marker-based AR is also relatively easier due to the availability of several libraries which support the development process (Bacca et al., 2014). The use of static markers decreases the required tracking work and reduces the number of objects that need to be detected (Chen \& Tsai, 2012). Therefore, using markers for educational purposes is recommended for providing students with a better learning experience until superior, cost-effective, and more reliable techniques for tracking are developed for markerless AR. Although the latter has not been widely used in educational settings $(21.4 \%$ in Primary and $14.3 \%$ in Secondary education), Microsoft Kinect sensors and similar technologies have been used for AR educational applications (Cai et al., 2016; Squire \& Jan, 2007). This is of great importance because they appear to provide some advantages in tracking and registering objects with markerless AR. Finally, locationbased AR applications are gaining momentum, possibly due to the availability of sensors in mainstream mobile devices that allow users' location and geographical position to inform the AR experience.

Table 8. Types of AR applied in compulsory education

\begin{tabular}{lcc}
\hline Primary education & Number of studies & Percentage (\%) \\
\hline Marker-based AR & 7 & 50.0 \\
Markerless AR & 3 & 21.4 \\
Location-based AR & 3 & 21.4 \\
Not specified in the study & 1 & 7.2 \\
\hline Secondary education & Number of studies & Percentage (\%) \\
\hline Marker-based AR & 5 & 71.4 \\
Markerless AR & 1 & 14.3 \\
Location-based AR & 1 & 14.3 \\
\hline
\end{tabular}

Results in Table 9 unveil that the devices used for ARGBL activities are primarily smartphones, tablets, and computers with video cameras. Mobility seems to be a key point, as $64.2 \%$ of studies in Primary education utilised either tablets (Atwood-Blaine \& Huffman, 2017; Efstathiou et al., 2017; Tobar-Munoz et al., 2017; Chen et al., 2016; Chiang et al., 2014) or smartphones (Hwang et al., 2016; Laine et al., 2016; Zhang et al., 2014; Furió et al., 2013) instead of computers with cameras. A possible explanation for this might be that the majority of the reviewed studies covered Natural Science and took place outside of the conventional classroom or during a field trip, where mobile devices are more convenient. On the other hand, computers with cameras are more extensively used in Secondary education $(57.1 \%)$. This could be attributed to the fact that field trips are less frequent in Secondary education, which could possibly explain why most of the reviewed studies took place in the classroom, where mobility is less of an issue. It remains to be seen whether new sophisticated technologies such as smart glasses, which have yet to reach the mainstream, are going to change the field of ARGBL and become the dominant technologies in the future.

Table 9. Instructional settings and devices used in ARGBL

\begin{tabular}{lcc}
\hline Primary education & Number of studies & Percentage (\%) \\
\hline Tablets & 5 & 35.7 \\
Smartphones & 4 & 28.5 \\
Computer (laptop/desktop) combined with a video camera & 4 & 28.5 \\
Motion sensing input devices (e.g., Microsoft Kinect) & 1 & 7.3 \\
\hline Secondary education & Number of studies & Percentage (\%) \\
\hline Tablets & 0 & 0.0 \\
Smartphones & 3 & 42.9 \\
Computer (laptop/desktop) combined with a video camera & 4 & 57.1 \\
Motion sensing input devices (e.g., Microsoft Kinect) & 0 & 0.0 \\
\hline
\end{tabular}

Table 10 presents the data collected on the limitations of ARGBL in educational settings. According to these, the most observed limitation in the reviewed studies is the fact that "teachers cannot manipulate the same system for different educational subjects (lack of interdisciplinary programs)" (35.7\% in Primary and $42.9 \%$ in Secondary education). Students may feel frustrated if the application does not track or display data properly, or if they struggle to use the markers or the device to view the augmented information. To overcome this limitation, improvements to the algorithms and/or hardware used for image tracking and processing must be made. As both 
easy-to-use and intuitive user interfaces (UI) are also instrumental for a rewarding AR experience, it is imperative that usable UI specifically tailored for young audiences are developed.

Another reported limitation was that "students paid too much attention to virtual information" (21.4\% in Primary and $28.5 \%$ in Secondary education) due to the novelty of this technology, which may cause loss of interest when the novelty factor wears off. This can occur because "complex AR systems may have a modest learning curve" (14.3\% in both Primary and Secondary education). Other reported limitations include "too short periods of assessment to measure student learning performance" (14.3\% in Primary education) and the fact that "teachers need to develop additional learning material exclusive to the AR needs" (14.3\% in both Primary and Secondary education). So, before major progress in the ARGBL area can be achieved, guidelines for designing usable AR-based educational experiences for a variety of subjects must be developed. Since teaching quality significantly affects student attention, the learning material should be clear, understandable, comprehensive, and relevant to the learning objectives. Case studies focusing on learning and teaching catering to the needs of specific teaching topics/themes would help identify the most suitable elements to focus on. These should be accompanied by further research in the development of intuitive and user-friendly AR authoring tools that do not rely heavily on programming so that teachers can create their AR content more easily.

Table 10. Limitations of ARGBL in educational settings

\begin{tabular}{lcc}
\hline Primary education & $\begin{array}{c}\text { Number of } \\
\text { studies }\end{array}$ & $\begin{array}{c}\text { Percentage } \\
(\%)\end{array}$ \\
\hline $\begin{array}{l}\text { Teachers cannot manipulate the same system for different educational subjects } \\
\text { (lack of interdisciplinary programs) }\end{array}$ & 5 & 35.7 \\
Students paid too much attention to virtual information (novelty factor) & 3 & 21.4 \\
Teachers need to develop additional learning material exclusive to the AR needs & 2 & 14.3 \\
Complex AR systems may have a modest learning curve & 2 & 14.3 \\
Too short periods of assessment to measure student learning performance & 2 & 14.3 \\
\hline Secondary education & Number of & Percentage \\
& studies & $(\%)$ \\
\hline Teachers cannot manipulate the same system for different educational subjects & 3 & 42.9 \\
(lack of interdisciplinary programs) & 2 & 28.5 \\
Students paid too much attention to virtual information (novelty factor) & 1 & 14.3 \\
Teachers need to develop additional learning material exclusive to the AR needs & 1 & 14.3 \\
Complex AR systems may have a modest learning curve & 2 \\
\hline
\end{tabular}

\section{Discussion and conclusions}

The educational potential of AR technology is significant, because of the benefits that influence the students' cognitive acceleration, the increase to their self-management, and the enhancement to their engagement in practice-based activities. Specifically, ARGBL can be useful for educators to recognise the educational potential and affordances in their different disciplines. Researchers seem to have taken notice, as published studies about ARGBL in Primary education particularly have been significantly increased in the last couple of years, with almost $65 \%$ ( 9 out of 14) of the reviewed studies having been published after 2016. Therefore, this systematic literature review intends to contribute to an educational design by providing evidence of ARGBL applications' potential to support teaching and learning across different disciplines in Primary and Secondary education. It also aspires to assist and inspire researchers and educators towards adopting AR technologies in their practice. To summarise, the main findings of this review are as follows.

GBL approaches in the reviewed studies varied, but often included location-based ARGBL (e.g., Atwood-Blaine \& Huffman 2017; Kamarainen et al. 2013). Other cases encompassed the narrative aspect of the game and the way AR could support this (e.g., Laine et al. 2016; Bressler \& Bodzin 2013). In regard to the disciplines where ARGBL was applied the most in Primary and Secondary education, STEM led the way. ARGBL is suitable for teaching Science and other STEM subjects, as it offers the ability to bring to life invisible, abstract, and complex concepts. This can be seen through 3D or other visual scientific phenomena that could not be observed without a specialised approach such as AR. Social science fields, including history, archaeology, linguistics, and geography, as well as arts and tourism can become more engaging if AR is combined with geolocation to provide locationtriggered contextual information to students. For example, an interactive scavenger hunt or a guided historic tour are activities that can facilitate problem-solving, inquiry/discovery learning, and "augmented" interaction with the real world, thus impacting greatly the learning experience of students. Additionally, language learning can be more fun through the use of AR flashcards, while a smart AR globe could teach children about countries and 
cultures from around the world in an interactive and playful way. Nevertheless, more cases studies are required in order to understand how to design ARGBL experiences for different topics according to the skills of learners.

Marker-based AR is the most commonly used type of AR in Primary and Secondary education, followed closely by location-based AR, owing to the availability of sensors in mobile devices such as gyroscopes, accelerometers, and GPS (Chen \& Tsai, 2012; Hung et al., 2016). This might change in the near future though, as in 2017 companies such as Apple and Google launched their own smartphone-driven AR platforms, ARKit and ARCore, which will potentially make for easier and better implementation of markerless applications. Additionally, Microsoft, Google, Intel, Vuzix, Magic Leap and others have been working to bring AR to the consumer in eyeglass form (Rauschnabel, 2018). Consequently, it is safe to conclude that over the next years markerless AR will be the mainstream of this technology along with location-based applications.

The technologies used in the reviewed studies include tablets (e.g., Efstathiou et al., 2017; Atwood-Blaine \& Huffman, 2017; Echeverría et al., 2012), mobile phones (Hwang et al., 2016; Zhang et al., 2014; Bressler \& Bodzin, 2013; Kamarainen et al., 2013), computers with webcams (DiSerio et al., 2013; Hsiao et al., 2012), ceiling mounted cameras, AR-enhanced books, and AR-manipulated weather stations. All these different technologies suggest a broad and diverse consideration of AR within GBL pedagogy, but if smart glasses become a success in the near future, the potential for education is mind-blowing. Experimentation and simulation tools can potentially become the next big thing for ARGBL applications since they provide a more realistic and interactive environment for students.

From an instructional design perspective, this study suggests that interactive learning challenges using AR technology can be designed to support different activity and pedagogy in various places and learning spaces such as the classroom, field trips, and the wider school environment (both indoor and outdoor). Motivation and enrichment of the learning experience appear to be the two pillars of ARGBL, which can lead to clear enjoyment, knowledge gain, augmented interaction, increased engagement, and enhanced collaboration (e.g., Atwood-Blaine \& Huffman 2017; Ruiz-Ariza et al., 2017; Echeverría et al. 2012). With the use of AR technology, students can improve their learning performance (Efstathiou et al., 2017; Hung et al., 2017; Hwang et al., 2016; Chen \& Tsai, 2012; Enyedy et al., 2012), show increased motivation (Tobar-Munoz et al., 2017; Di Serio et al., 2013), or achieve both (Cai et al., 2016; Chen et al., 2016; Hsiao et al., 2013; Chiang Et al., 2014, Kamarainen et al., 2013), partly due to improved positive attitudes towards the learning process. However, the majority of the reviewed studies came to these positive findings after comparing their ARGBL approach to traditional learning (Atwood-Blaine \& Huffman, 2017; Ruiz-Ariza et al., 2017; Chen, \& Tsai,2012; Hsiao et al., 2012); only a few studies compared it to mobile GBL (Furió et al., 2013; Hsiao et al., 2013), inquiry-based mobile learning (Chiang et al., 2014) or VRbased applications (Furió et al., 2013). This lack of data creates difficulty in identifying whether the benefits of the learning experience were due to specific GBL approaches, the use of AR technologies, or the combination of both.

Teachers who may find ARGBL integration within their lessons more challenging are those who may not be very experienced in the use of mobile devices in educational settings. When designed with the pedagogies of learning in mind, such technological approaches should support collaborative knowledge-based engagement and enable co-constructed knowledge to occur in the class environment. Additionally, a substantial body of contemporary research (Efstathiou et al., 2017; Chen \& Tsai, 2012; Wu et al., 2013) has reported that there is also a need for learning theories to inform the teaching methods. Suggested theories to consider while creating interactive ARGBL experiences include Constructionism and Activity Theory. This research also highlights important practical implications, especially for developers and teachers who want to use ARGBL applications in their classes. There is a need for new methods for creating interactive 3D content for AR learning environments (Bacca et al., 2014; Chang et al., 2014). The development of AR authoring tools that require a limited amount of coding could potentially allow teachers with limited technical skills to create content capable of facilitating and enhancing the learning process. Further research is also required on improving the user experience and knowledge construction processes in ARGBL applications in order to drive the students' learning forward. This means that educators and AR game designers need to understand how to create AR learning experiences tailored to the topic being taught, while also taking into consideration the skill set of the learners. Arguably, AR has the potential to reduce the financial cost of implementing learning activities which involve technological tools to support student engagement. Nevertheless, unless there is a shift in the quality culture of educational institutions which will value or reward teaching innovation, teachers will probably remain reluctant to adopt ARGBL, as this will add to the already heavy workload they have to endure.

The present systematic review underlines specific educational areas in Primary and Secondary education where the application of AR game-based approaches have not yet been investigated. Further research is still required 
into different facets of game-based AR applications, including the development of theoretical frameworks and evaluation methods to help establish the pedagogy of AR game-based applications within Primary and Secondary school-based classrooms. Longitudinal studies with long-term analysis of the learning experiences could also provide important insights into the suitability of this technology for specific learning subjects. Lastly, there was not identified any system regarding the potential use of AR for GBL to be considered for students with special needs and there is need to be conducted a study about this topic in the future.

\section{References}

Adams B., S., Freeman, A., Giesinger Hall, C., Cummins, M. \& Yuhnke, B. (2016). NMC/CoSN Horizon Report: 2016 K-12 edition. Austin, TX: The New Media Consortium.

Akçayır M. \& Akçayır G. (2017). Advantages and challenges associated with augmented reality for education: A systematic review of the literature. Educational Research Review 20, 1-11.

Alakärppä, I., Jaakkola, E., Väyrynen, J., \& Häkkilä, J. (2017). Using nature elements in mobile AR for education with children. In Proceedings of the 19th International Conference on Human-Computer Interaction with Mobile Devices and Services (MobileHCI '17). Article 41. ACM, New York, NY, USA.

Atwood-Blaine, D., \& Huffman, D. (2017). Mobile gaming and student interactions in a science center: The future of gaming in science education. International Journal of Science and Mathematics Education, Supplement 1, 4565 .

Azuma, R.T. (1997). A survey of augmented reality. Presence, 6(4), 355-385.

Bacca, J., Baldiris, S., Fabregat, R., Graf, S., \& Kinshuk. (2014). Augmented reality trends in education: A systematic review of research and applications. Educational Technology \& Society, 17 (4), 133-149.

Blippar (2018). Blippar. https://www.blippar.com/. Accessed 20 March 2018.

Borowiecki, K.J., \& Bakhshi, H. (2017). Did you really take a hit? Understanding how video games playing affects individuals. Research in Economics. https://doi.org/10.1016/j.rie.2017.06.004

Bressler, D. M., \& Bodzin, A. M. (2013). A mixed methods assessment of students' flow experiences during a mobile augmented reality science game. Journal of Computer Assisted Learning, 29(6), 505-517.

Bujak, K. R., Radu, I., Catrambone, R., MacIntyre, B., Zheng, R., \& Golubski, G. (2013). A psychological perspective on augmented reality in the mathematics classroom. Computers \& Education, 68, 536-544.

Cai, S., Chiang, F., Sun, Y., Lin, C. \& Lee, J. (2016). Applications of augmented reality-based natural interactive learning in magnetic field instruction. Interactive Learning Environments, 25(6), 778-791.

Cai, S., Wang, X., \& Chiang, F.-K. (2014). A case study of augmented reality simulation system application in a chemistry course. Computers in Human Behavior, 37, 31-40.

Chang, H., Hsu, H. \& Wu, H. (2014). A comparison study of augmented reality versus interactive simulation technology to support student learning of a socioscientific issue. Interactive Learning Environments, 24(6), 11481161 .

Chang, R., Chung, L. \& Huang, Y. (2014). Developing an interactive augmented reality system as a complement to plant education and comparing its effectiveness with video learning. Interactive Learning Environments, 24(6), 1245-1264.

Chang, K.-E., Chang, C.-T., Hou, H.-T., Sung, Y.-T., Chao, H.-L., \& Lee, C.-M. (2014). Development and behavioral pattern analysis of a mobile guide system with augmented reality for painting appreciation instruction in an art museum. Computers \& Education, 71, 185-197.

Chen, C.-H., Chou, Y.-Y. \& Huang, C.-Y. (2016). An Augmented-Reality-Based Concept Map to Support Mobile Learning for Science. The Asia-Pacific Education Research, 25(4), 567-578.

Chen, C.-M., \& Tsai, Y.-N. (2012). Interactive augmented reality system for enhancing library instruction in elementary schools. Computers \& Education, 59(2), 638-652.

Chen, P., Liu, X., Cheng, W., \& Huang, R. (2017). A review of using Augmented Reality in education from 2011 to 2016. In: Popescu E. et al. (eds) Innovations in Smart Learning. Lecture Notes in Educational Technology. Springer, Singapore, 13-18.

Chiang, T.-H.-C., Yang, S.-J.-H. \& Hwang, G.-J. (2014). An Augmented Reality-based Mobile Learning System to Improve Students' Learning Achievements and Motivations in Natural Science Inquiry Activities. Educational Technology \& Society, 17(4), 352-365.

Colley, A., Thebault-Spieker, J., Lin, A.Y., Degraen, D., Fischman, B., Häkkilä, J., Kuehl, K., Nisi, V., Nunes, N.J., Wenig, N., Wenig, D., Hecht, B., \& Schöning, J. (2017). The Geography of Pokémon GO: Beneficial and Problematic Effects on Places and Movement. In Proceedings of the 2017 CHI Conference on Human Factors in Computing Systems (CHI '17). ACM, New York, NY, USA, 1179-1192. https://doi.org/10.1145/3025453.3025495

Di Serio, A., Ibáñez, M.B., \& Kloos, C.D. (2013). Impact of an augmented reality system on students' motivation for a visual art course. Computers \& Education, 68, 586-596. https://doi.org/10.1016/j.compedu.2012.03.002 
Dunleavy, M., Dede, C., \& Mitchell, R. (2009). Affordances and limitations of immersive participatory augmented reality simulations for teaching and learning. Journal of Science Education and Technology, 18(1), 722. https://doi.org/10.1007/s10956-008-9119- 1

Dunleavy, M., \& Dede, C. (2014). Augmented reality teaching and learning. In the Handbook of Research for Educational Communications and Technology (4th ed.). Spector J. Michael, M. David Merrill, Jan Elen \& M. J. Bishop (eds.). Springer, New York, 735-745.

Echeverría, A., Améstica, M., Gil, F., Nussbaum, M., Barrios, E., \& Leclerc, S. (2012). Exploring different technological platforms for supporting co-located collaborative games in the classroom. Computers in Human Behavior, 28(4), 1170-1177.

Efstathiou, I., Kyza, E., \& Georgiou, Y. (2017). An inquiry-based augmented reality mobile learning approach to fostering Primary school students' historical reasoning in non-formal settings. Interactive Learning Environments, 26(1), 22-41.

Enyedy, N., Danish, J.A., Delacruz, G., \& Kumar, M. (2012). Learning physics through play in an augmented reality environment. International Journal of Computer-Supported Collaborative Learning, 7(3), 347-378.

Fotaris, P., Mastoras, T., Leinfellner, R., \& Rosunally, Y. (2016). Climbing Up the Leaderboard; An Empirical Study of Applying Gamification Techniques to a Computer Programming Class. Electronic Journal of eLearning, 14 (2), 94-110.

Fotaris, P., Pellas, N., Kazanidis, I., \& Smith, P. (2017). A systematic review of Augmented Reality game-based applications in Primary education. Proceedings of the 11th European Conference on Games Based Learning (ECGBL17), Graz, Austria, 181-190.

Furió, D., González-Gancedo, S., Juan, M.-C., Seguí, I., \& Rando, N. (2013). Evaluation of learning outcomes using an educational iPhone game vs. traditional game. Computers \& Education, 64, 1-23.

Gee, J.P. (2008). Learning and games. In: Salen, K., (Ed.) The ecology of games: connecting youth, games and learning. MIT Press: Cambridge, MA.

Hamari, J., Shernoff, D. J., Rowe, E., Coller, B., Asbell-Clarke, J., \& Edwards, T. (2016). Challenging games help students learn: an empirical study on engagement, flow and immersion in game-based learning. Computers in Human Behavior, 54, 170-179.

HP Reveal (2018). HP Reveal. https://www.hpreveal.com/. Accessed 20 March 2018.

Hsiao, H.-S., Chang, C.-S., Lin, C.-Y., \& Wang, Y.-Z. (2013): Weather observers: a manipulative augmented reality system for weather simulations at home, in the classroom, and at a museum, Interactive Learning Environments, 24(1), 205-223. https://doi.org/10.1080/10494820.2013.834829

Hsiao, K.-F., Chen, N.-S., \& Huang, S.-Y. (2012). Learning while exercising for science education in augmented reality among adolescents. Interactive Learning Environments, 20(4), 331-349.

Huang, T.-C., Chen, C.-C., \& Chou, Y.-W. (2016). Animating eco-education: To see, feel, and discover in an augmented reality-based experiential learning environment. Computers \& Education, 96, 72-82.

Hung, Y.-H., Chen, C.-H., \& Huang, S.-W. (2017). Applying augmented reality to enhance learning: a study of different teaching materials. Journal of Computer Assisted Learning, 33(3), 252-266.

Hwang, G.-J., Wu, P.-H., Chen, C.-C., \& Tu, N.-T. (2016). Effects of an augmented reality-based educational game on students' learning achievements and attitudes in real-world observations, Interactive Learning Environments, 24(8), 1895-1906.

Internet Advertising Bureau (IAB) (2014). Gaming Revolution. https://iabuk.net/research/library/gamingrevolution. Accessed 12 January 2018.

International Data Corp. (2017). Worldwide Semi-annual Augmented and Virtual Reality Spending Guide, October 2017. https://www.idc.com/getdoc.jsp?containerId=prUS43248817. Accessed 25 March 2018.

Juan, M.C., Furió, D., Alem, L., Ashworth, P., \& Cano, J. (2011). ARGreenet and Basic-Greenet: Two mobile games for learning how to recycle. In Proceedings of the 19th International Conference on Computer Graphics, Visualization and Computer Vision (WSCG'2011), 25-32.

Kamarainen, A.M., Metcalf, S., Grotzer, T., Browne, A. Mazzuca, D., Tutwiler, M.S, \& Dede, C. (2013). EcoMOBILE: Integrating augmented reality and probeware with environmental education field trips. Computers \& Education, 68, 545-556.

Kitchenham, B.A. (2007). Guidelines for performing systematic literature reviews in software engineering Version 2.3, EBSE Technical Report, Keele University and University of Durham.

Koutromanos, G. Sofos, A., \& Avraamidou, L. (2016). The use of augmented reality games in education: a review of the literature. Educational Media International, 52(4), 253-271. https://doi.org/ 10.1080/09523987.2015.1125988

Laine, T., Nygren, E., Dirin, A. \& Suk, H. (2016). Science Spots AR: a platform for science learning games with augmented reality. Education Technology \& Research Development, 64(2), 507-531.

Liberati, A. et al. (2009). The PRISMA statement for reporting systematic reviews and meta-analyses of studies that evaluate healthcare interventions: Explanation and elaboration. BMJ, 339: b2700. https://doi.org/10.1136/bmj.b2700 
Liou, H., Yang, S., Chen, S., \& Tarng, W. (2017). The Influences of the 2D image-based augmented reality and virtual reality on student learning. Educational Technology \& Society, 20(3), 110-121.

Liu, T.-Y., \& Chu, Y.-L. (2010). Using ubiquitous games in an English listening and speaking course: Impact on learning outcomes and motivation. Computers \& Education, 55(2), 630-643. https://doi.org/10.1016/j.compedu.2010.02.023

Moher, D., Liberati, A., Tetzlaff, J., \& Altman, D. G. (2009). Preferred reporting items for systematic reviews and meta-analyses: The PRISMA statement. PLoS Medicine, 6(7), e1000097.

Palmarini, R., Erkoyuncua, J., Roya, R., \& Torabmostaedi, H. (2018). A systematic review of augmented reality applications in maintenance, Robotics and Computer-Integrated Manufacturing, 49, 215-228.

Papastergiou, M. (2009). Digital game-based learning in high school computer science education: impact on educational effectiveness and student motivation. Computers \& Education, 52(1), 1-12.

Pellas, N., Konstantinou, N., Kazanidis, I., \& Georgiou, G. (2016). Exploring the educational potential of threedimensional multi-user virtual worlds for STEM education: A mixed-method systematic literature review. Education \& Information Technologies, 22(5), 2235-2279.

Pellas, N., \& Vosinakis, S. (2018). The effect of computer simulation games on learning introductory programming: A comparative study on high school students' learning performance by assessing computational problem-solving strategies. Education \& Information Technologies. https://doi.org/10.1007/s10639-018-9724-4 Phipps, L., Alvarez, V., de Freitas, S., Wong, K., Baker, M., \& Pettit, J. (2016). Conserv-AR: A Virtual and Augmented Reality Mobile Game to Enhance Students' Awareness of Wildlife Conservation in Western Australia. In Proceedings of the 15 th World Conference on Mobile and Contextual Learning (mLearn 2016), Sydney, Australia, 1, 214-217.

Prensky, M. (2006). Digital natives. Learning in the Digital Age. 63, 8-13.

Punch, K. (1998). Introduction to Social Research: Quantitative and Qualitative Approaches. London: Sage

Radu, I. (2014). Augmented reality in education: a meta-review and cross media analysis. Personal and Ubiquitous Computing, 18, 1533-1543.

Rauschnabel P.A. (2018) A conceptual uses \& gratification framework on the use of Augmented Reality smart glasses. In: Jung T., tom Dieck M. (eds) Augmented Reality and Virtual Reality. Progress in IS. (pp. 211-227). Springer, Cham

Ruiz-Ariza A., Casuso R.A., Suarez-Manzano S., \& Martínez-López E.J. (2017). Effect of augmented reality game Pokémon GO on cognitive performance and emotional intelligence in adolescent young, Computers \& Education. https://doi.org/10.1016/j.compedu.2017.09.002

Russell, C. K., \& Gregory, D. M. (2003). Evaluation of qualitative research studies. Evidence Based Nursing, 6(2), 36-40. https://doi.org/10.1136/ebn.6.2.36

Santos, M. E. C., Chen, A., Taketomi, T., Yamamoto, G., Miyazaki, J., \& Kato, H. (2014). Augmented reality learning experiences: Survey of prototype design and evaluation. IEEE Transactions on Learning Technologies, 7(1), 38-56. https://doi.org/10.1109/TLT.2013.37

Sommerauer, P., \& Müller, O. (2014). Augmented reality in informal learning environments: a field experiment in a mathematics exhibition. Computers \& Education, 79, 59-68.

Squire K.D., \& Jan, M. (2007). Mad city mystery: developing scientific argumentation skills with a place-based augmented reality game on handheld computers. Journal of Science Education and Technology, 16(1), 5-29.

Steinkuehler, C., \& Squire, K. (2014). Videogames and Learning. The Cambridge Handbook of the Learning Sciences, 377-394.

Thomson Reuters Journal Citation Reports (2017). $\underline{\text { http://ipscience- }}$ help.thomsonreuters.com/incitesLiveESI/8275-TRS.html Accessed 23 August 2017

Tobar-Muñoz, H., Baldiris, S., \& Fabregat, R. (2017). Augmented Reality game-based learning: Enriching students' experience during reading comprehension activities. Journal of Educational Computing Research, 1-36. Wei, X., Weng, D., Liu, Y. \& Wang, Y. (2015). Teaching based on augmented reality for a technical creative design course. Computers \& Education, 81, 221-234.

Wu, H.-K., Lee, S. W.-Y., Chang, H.-Y. \& Liang, J.-C. (2013). Current status, opportunities and challenges of augmented reality in education. Computers \& Education, 62(3), 41-49.

Zhang, J., Sung, Y.-T., Hou, H.-T. \& Chang, K.-E. (2014). The development and evaluation of an augmented reality-based armillary sphere for astronomical observation instruction. Computers \& Education, 73(2), 178-188. 


\section{Appendix}

Table 0. The specific protocol executed in each database

\begin{tabular}{|c|c|c|}
\hline Database & Protocol & Note \\
\hline JSTOR & $\begin{array}{l}(((\text { learn or learning or engagement or learning } \\
\text { outcomes }) \\
<\text { in }>\text { ab })<\text { and }>((\text { Augmented reality or } \\
\text { Augmented reality games or Augmented reality } \\
\text { game-based learning })<\text { in }>\text { ab }))<\text { in }>\text { ab })<\text { and }> \\
((\text { qualitative or quantitative })) \\
<\text { and }>((\text { school or } \mathrm{k}-12)<\text { in }>\text { ab }))<\text { and }>(\text { pyr }>O \\
2000<\text { and }>\text { pyr }<0 \text { 2012) }\end{array}$ & Search on the field "Abstract". \\
\hline SCOPUS & $\begin{array}{l}\text { ab: ((teaching or learning or education or } \\
\text { educational) and (Augmented reality games or } \\
\text { Augmented reality game-based learning) and } \\
\text { (middle school or Primary or Secondary)) } \\
\text { Content Type > Journal Articles } \\
\text { Publication Date > Between Saturday, January 01, } \\
2012 \text { and Thursday, } \\
\text { September 30, } 2017\end{array}$ & $\begin{array}{l}\text { Search on the fields "Abstract", "Title" } \\
\text { and "Keywords". }\end{array}$ \\
\hline Science Direct & $\begin{array}{l}\text { (learning OR teach OR learn OR education OR } \\
\text { educational) <in> } \\
\text { Smart Search AND (Augmented reality game- } \\
\text { based learning or Augmented reality game-based } \\
\text { learning) <in> } \\
\text { Smart Search AND (Primary OR Secondary OR } \\
\text { k-12) <in> Smart Search AND } \\
\text { Date: between } 2012 \text { and } 2017 \text { AND } \\
\text { Limited to: PEER_REVIEWED } \\
\text { In Education Full Text }\end{array}$ & $\begin{array}{l}\text { Search on the field "Abstract". } \\
\text { - Term k-12 replaced by high school or } \\
\text { middle school by restriction of the } \\
\text { database. } \\
\text { - Terms "teach" and "learn" } \\
\text { suppressed limiting quantity of terms } \\
\text { used to search the database. Variations } \\
\text { to the terms removed were used and } \\
\text { can be identified that did not } \\
\text { compromise the result. }\end{array}$ \\
\hline ESCBO & $\begin{array}{l}\text { Publication Type: "Journal Articles" } \\
\text { and Full-Text Available }\end{array}$ & $\begin{array}{l}\text { Search on the field "Keywords (all } \\
\text { fields)". }\end{array}$ \\
\hline ERIC & $\begin{array}{l}\text { (Publication Date: 2012-2017) } \\
\text { ((Keywords: teaching OR Keywords: teach OR } \\
\text { Keywords: learn OR Keywords: } \\
\text { learning OR Keywords: education OR Keywords: } \\
\text { educational) and (Keywords: } \\
\text { Augmented reality OR Keywords: Augmented } \\
\text { reality OR Keywords: } 3 \text { Augmented reality games } \\
\text { OR Keywords: games and Augmented reality OR } \\
\text { Keywords: qualitative and quantitative research } \\
\text { method } \\
\text { OR Keywords: K-12) }\end{array}$ & $\begin{array}{l}\text { Search on the field "Keywords (all } \\
\text { fields)". }\end{array}$ \\
\hline Wiley & $\begin{array}{l}\text { ((learning or engagement or educational }) \\
<\text { in }>\text { ab })<\text { and }>((\text { augmented reality or AR } \\
\text { environments })<\text { in }>\text { ab })) \\
<\text { and }>((\text { Primary or Secondary or Higher } \\
\text { education })<\text { in }>\text { ab }))<\text { and }>(\text { pyr }>\text { O } 2000<\text { and }> \\
\text { pyr }<\text { O 2013) }\end{array}$ & - Search on the field "Abstract". \\
\hline Web of Science & $\begin{array}{l}\text { ((learning or K-12 education) } \\
<\text { in }>\text { ab) <and }>((\text { Augmented reality game-based } \\
\text { learning })<\text { in }>\text { ab })) \\
<\text { and }>((\text { Primary or Secondary })<\text { in }>\text { ab }))<\text { and }> \\
(\text { pyr }>\text { O } 2000<\text { and }>\text { pyr }<0 \text { 2013) }\end{array}$ & - Search on the field "Abstract". \\
\hline
\end{tabular}

